\title{
Analysis of factors affecting the pregnancy rate of mares after inseminations with cooled transported stallion semen
}

\section{Kareskoski, Maria}

2019-03-15

Kareskoski, M , Venhoranta , H, Virtala , A-M \& Katila , T 2019, ' Analysis of factors affecting the pregnancy rate of mares after inseminations with cooled transported stallion semen ' , Theriogenology , vol. 127 , pp. 7-14 . https://doi.org/10.1016/j.theriogenology.2018.12.036

http://hdl.handle.net/10138/308875

https://doi.org/10.1016/j.theriogenology.2018.12.036

cc_by_nc_nd

acceptedVersion

Downloaded from Helda, University of Helsinki institutional repository.

This is an electronic reprint of the original article.

This reprint may differ from the original in pagination and typographic detail.

Please cite the original version. 

with cooled transported stallion semen

3

4

5

6

7

8

9

10

11

12

13

14

15
Kareskoski Maria ${ }^{\mathrm{a}}$, Venhoranta Heli ${ }^{\mathrm{a}}$, Virtala Anna-Maija ${ }^{\mathrm{b}}$, Katila Terttu ${ }^{\mathrm{a}}$

${ }^{a}$ University of Helsinki, Faculty of Veterinary Medicine, Paroninkuja 20, 04920

Saarentaus, Finland

${ }^{\mathrm{b} U n i v e r s i t y ~ o f ~ H e l s i n k i, ~ F a c u l t y ~ o f ~ V e t e r i n a r y ~ M e d i c i n e, ~ P O ~ B o x ~ 66, ~} 00014$ Helsinki, Finland; anna-maija.virtala@helsinki.fi

Corresponding author: Katila Terttu, University of Helsinki, Paroninkuja 20, 04920

Saarentaus, Finland; terttu.katila@ helsinki.fi 
Artificial insemination (AI) with cooled stallion semen has increased markedly during the last decades in all countries, but fertility is often lower than when fresh semen or natural mating is used. The objective of this study was to examine field data (1634 inseminations, 523 Standardbred (SB) mares, 575 Finnhorse (FH) mares, and 90 stallions) using multivariable logistic regression for factors influencing the pregnancy rate $(\mathrm{PR})$ after $\mathrm{AI}$ with cooled transported semen from SB and $\mathrm{FH}$ stallions. The PR per cycle for the material was $47 \%$ : Finnhorses $42 \%$ and with a generalized linear mixed model, variables that affected the PR were breed, the number of inseminated estrus cycles, the percentage of progressively motile sperm (PMOT) in the ejaculate/AI dose at the time of shipment, and the number of progressively motile sperm in the AI dose at the time of insemination. In Standardbreds, variables that increased the per cycle PR were the number of AI per estrus cycle (multiple inseminations increasing the probability of pregnancy compared to only one insemination), the number of inseminated cycles, and PMOT in the AI dose at the time of insemination. In Finnhorses, the number of AI per estrus cycle (two and three inseminations increasing the probability of pregnancy compared to only one), the number of spermatozoa in the ejaculate and in the AI dose, and PMOT in the ejaculate/AI dose at the time of shipment increased the per cycle PR. Non-significant factors for the whole material included the type of artificial vagina (open-ended or closed), transport time, place of AI (stud farm or home stable), insemination done by veterinarian or technician, weekday, month, age of the mare (all age classes combined), age of the stallion, ejaculate parameters (sperm concentration, total number of sperm), and insemination dose parameters (volume 
proportion of seminal plasma, sperm concentration, PMOT, total number of sperm). In conclusion, breed, breeding opportunity in more than one cycle, more than one insemination/estrus, PMOT of the ejaculate/AI dose and the number of progressively motile sperm in the AI dose at the time of insemination are important for the outcome of inseminations with cooled semen.

Keywords: horse, fertility, insemination dose, seminal plasma, progressive sperm

\section{Introduction}

The use of artificial insemination (AI) by transported cooled semen has markedly increased during the last decades in all countries, whereas on-site AI and natural mating have become less popular. From the year 1991 to 2005, the use of transported semen increased from 15 to $43 \%$ of all registered matings among Standardbreds in Finland [1].

Successful storage of fresh semen for transportation requires dilution by adding extender and cooling of semen [2]. The optimal temperature for semen storage is from $+5^{\circ} \mathrm{C}$ to $+10^{\circ} \mathrm{C}$, which temperature the styrofoam boxes used in Finland keep for $33 \mathrm{~h}$ in room temperature [3]. In practice, the boxes are exposed to various ambient temperatures, but in an Austrian study, the average temperature was still $9.8^{\circ} \mathrm{C}$ after an average transport time of $26.5 \mathrm{~h}$ [4]. The duration of transport varies but typically it is around $24 \mathrm{~h}$, frequently from 12 to $48 \mathrm{~h}$. 
Dilution of semen is necessary to decrease the sperm concentration; $25 \times 10^{6} / \mathrm{mL}$ maintains motility best during storage [5] but concentrations between 50 and $100 \mathrm{x}$ $10^{6} / \mathrm{mL}$ are more practical because of smaller volumes in the transport containers [6]. Another important goal in the dilution of semen is to decrease the volume proportion

A reduction of SP proportion is easily accomplished by adding extender to the semen, but concentrating the semen may be necessary, if the initial sperm concentration is low. A quick and practical concentration method is fractionated semen collection with open-ended artificial vagina (AV). In this method, semen is collected directly from the urethra using a large funnel to direct the desired jets into the collection device. The Krakow model AV developed by Marian Tischner was easily available in Finland when AI started in the early 1980's and it is still commonly used. Semen concentration and volume decrease with each successive jet during the ejaculation [12]. Usually the first two or three jets are collected, and additional advantages are avoidance of gel fractions and bacteria [13, 14]. 
It is to be expected that extra handling of semen, cooling and long storage decrease the quality and fertilizing capacity of sperm. When compared to on-site AI, pregnancy rates (PR) after AI with transported semen are significantly lower $[1,15]$. To compensate for the decrease in semen quality during storage, larger AI doses $(0.5$ to $1 \times 10^{9}$ sperm) are recommended for shipped semen [16], in Finland the recommendation is $1 \times 10^{9}$ progressively motile spermatozoa.

There are large differences between stallions in initial semen quality $[17,18]$, but particularly in the tolerance for cooled storage [15]. The center responsible for semen collection and handling has a profound effect on semen quality parameters at the time of AI [4]. There are also many other important reasons for the reduction in fertility that are not related to the stallion, such as inadequate mare management and veterinary care [16].

The objective of this study was to examine field data using multivariable logistic regression for factors influencing pregnancy rates after inseminations with cooled transported semen.

\section{Material and methods}

The data, 3557 inseminations, originate from all reported inseminations with cooled transported semen of Finnhorses (FH) and Standardbred (SB) trotters in Finland during the year 2007. Practically all matings are reported each year to the Finnish trotting and breeding association Suomen Hippos, as only foals born from registered matings are registered and allowed to race. 
In Finland, a form is enclosed in every semen transport container to give information

118 to the inseminator about the ejaculate of the stallion, preparation of the AI dose and the type of AV used as well as the time of semen collection. The form is returned to the semen collection centre with information regarding inseminated mares, inseminator, place and time of AI and progressive sperm motility (PMOT), if possible. One copy is sent to Suomen Hippos at the end of the season. We requested and received all copies from Suomen Hippos from one breeding season for analysis. The mating records are available for everyone and are published yearly by Suomen In Finland, semen is available on Mondays, Wednesdays and Fridays meaning that mares are usually inseminated every other day until ovulation - apart from the weekend. For each insemination, the following data were calculated and recorded for both the original ejaculate and the insemination dose prepared from the ejaculate: volume $(\mathrm{mL})$, sperm concentration $\left(10^{6} \mathrm{sperm} / \mathrm{mL}\right)$, total number of spermatozoa $\left(10^{9}\right)$, PMOT (\%, subjective assessment with light microscopy) and number of

134 reported for 781 inseminations allowing the calculation of the number of progressively motile sperm at insemination. The AI doses were classified according to SP content: not more than $25 \%, 25$ to $33 \%$, or at least $34 \%$ SP. Per cycle pregnancy rates were determined using the forms: new semen orders and inseminations indicated a previous non-pregnant cycle. The result of the last estrus was based on foaling results from Suomen Hippos: all mares reported having foaled or aborted were considered pregnant. 
142 The following factors were included in the analysis: breed (FH or SB), type of AV

143 (open-ended or closed), transport time (h), place of AI (stud farm/clinic or home

144 stable), insemination done by veterinarian or technician, number of AI cycles,

145 number of inseminations per cycle, weekday, month, age of the mare, age of the

146 stallion, ejaculate parameters (sperm concentration, total number of sperm, PMOT),

147 and insemination dose parameters at the time of shipment (volume proportion of SP,

148 sperm concentration, PMOT, total number of sperm, and number of progressively

149 motile sperm) and at the time of insemination (PMOT and the number of

150 progressively motile sperm), and the outcome of the insemination (pregnant or non-

151 pregnant cycle). Progressive sperm motility of the ejaculate and of the AI dose at the

152 time of sending is the same.

153

154 All warmblood riding horses, horses of unknown breed, and insemination forms with

155 incorrect calculations or deficient or incomprehensive information were excluded.

156 Insemination forms with the following extreme values were also excluded: sperm

157 concentration more than $500 \times 10^{6} \mathrm{sperm} / \mathrm{mL}$ in ejaculates collected with a closed

$158 \mathrm{AV}$, sperm concentration more than $1000 \times 10^{6} \mathrm{sperm} / \mathrm{mL}$ in ejaculates collected

159 with an open-ended AV, total number of spermatozoa/ejaculate more than $20 \times 10^{9}$,

160 or progressive motility before storage more than $80 \%$. Six stud farms had had less

161 than ten shipments, wherefore their data of 20 shipments were also excluded. All

162 records of one studfarm were excluded because the examination of semen was

163 obviously not correctly done and subsequent dilution calculations were also wrong.

164 Some of the report forms had been filled in incompletely, and therefore the number

165 of observations vary between parameters. If the mare had been inseminated more 
than once during the same estrus, only the last insemination dose was included in the calculation of the PR per cycle resulting in 1634 last inseminations, 523 Standarbred mares, 575 Finnhorse mares and 90 stallions. All inseminations, a total of 2928 inseminations, were assessed for the number of inseminations per season and per estrus. The 95\% confidence intervals (CI) for pregnancy rates were calculated with Wilson's method [19] using an internet-based epidemiological calculator [20]. After description of the data, the association of each factor separately with the per cycle PR (mare pregnant or not) was calculated using crude logistic regression analyses with generalized linear mixed model in the SAS software (GLIMMIX procedure, SAS Institute Inc., Cary, NC, USA); mare, stallion and stud farm were included as random effects. Factors with a Wald's p-value $<0.2$ were included in multivariable multilevel logistic regression analyses with generalized linear mixed models. Random intercepts for mare, stallion and stud farm were included in logistic models to account for the hierarchical structure of the data. In multivariable models, factors with Wald's $\mathrm{p} \leq 0.05$ were considered significant. Several multivariable models were created since all factors describing the ejaculate could not be included in same model if they biologically represent the same phenomenon.

\section{Results} The pregnancy rate per cycle of the whole material was $47.0 \%$ : FH $42.1 \%$ and SB $52.8 \%$; the difference was significant when assessed with 95\% CIs (Table 1). Foaling rates were $59.4 \%$ for $\mathrm{FH}$ and $73.5 \%$ for $\mathrm{SB}, 65.9 \%$ for the whole material as 
reported by Suomen Hippos. The pregnancy rates for all other categorical variables are shown in the same table. Tables $2 \mathrm{a}$ and $2 \mathrm{~b}$ show descriptive statistics for semen quality and inseminations resulting in pregnancy or non-pregnancy separately for the two breeds. It seems that in the Standardbreds semen volume, sperm concentration and PMOT of the ejaculate, as well as PMOT at the time of insemination, were higher than in the Finnhorses both for pregnant and non-pregnant mares.

197

\subsection{Crude logistic regression analyses}

Variables that differed significantly between pregnant and non-pregnant mare groups in the crude logistic regression analyses were breed, the number of inseminated estrus cycles, age of the mare (2-9 vs. 17-22 years), PMOT in the ejaculate/AI dose at the time of shipment, and PMOT and the number of progressively motile sperm in the AI dose at the time of insemination (Table 3).

\subsection{Multivariable logistic regression analyses}

In the multivariable logistic regression models, variables that increased significantly the PR were breed, the number of inseminated cycles, PMOT in the ejaculate/AI dose, and the number of progressively motile sperm in the AI dose at the time of insemination (Table 4).

In the FH population, the number of inseminations per estrus cycle (two and three inseminations increasing the probability of pregnancy compared to only one insemination), higher numbers of spermatozoa in the ejaculate and in the AI dose, and higher PMOT in the ejaculate/AI dose increased the per cycle PR (Table 5). In the SB population, variables that increased the per cycle PR were the number of 
inseminations per estrus cycle (multiple inseminations increasing the probability of pregnancy compared to only one insemination), the number of cycles ( $\geq 2$ inseminated cycles better than one cycle), and higher PMOT in the AI dose at the time of insemination (Table 5).

\section{Discussion}

Breed had a significant effect on the per cycle PR, with the FH having a lower per cycle PR (42\%) than the SB (53\%). In addition to genetic traits within a breed, this is likely to be related to differences in mare management and to selection of mares to the breeding population. In the study of Langlois and Blouin [21], French draught breeds had lower foaling rates than saddle breeds and trotters, possibly related to amateurism, dystocia, and differences in the reporting of mating and born foals. Similarly, FH breeders are often less professional than SB breeders, which may affect mare management and the use of veterinary expertise.

\section{Mare age}

Katila et al. [1] reported lower foaling rates for the FH than for the SB in Finland (all breeding methods included). This was explained by a different structure of the mare populations: FH mares were older, and there were more barren mares and fewer foaling mares in the FH mare population compared to the SB. The FH seemed to enter the barren mare category at a younger age and the maiden mare category at an older age than the SB. Also in the present study, the FH mares were about one year older than the SB mares. The negative effect of ageing on mare fertility has been reported in all studies where mare age has been included as a factor [1,21-27]. Age 
affects many aspects of reproduction, such as uterine function (uterine contractility, intrauterine fluid accumulation, endometrial inflammation and fibrosis), PR and pregnancy loss [22].

In our models, age was only almost significant (the youngest mares from 2 to 9 years having a higher PR than the oldest mares from 17 to 22 years). Its p-value increased to being clearly not significant, if the variable called "Number of progressively motile spermatozoa in the insemination dose $\left(10^{9}\right)$ at the time of insemination" was included in the model. This variable had to be included since it had a confounding effect on the "Progressive sperm motility in the ejaculate/AI dose (\%)" almost doubling its odds ratio from 6 to 12-14; therefore, these both had to be included in the model. Because mare age is so important for fertility, we included it into our multivariable models, regardless of its low significance.

\section{Stallion age}

Finnhorse stallions were approximately one year older than SB stallions, but stallion age did not come out as a significant factor in our analysis. However, Dowsett and Knott [18] reported that both age and breed of the stallion exerted significant effects on semen parameters. In our model, the total number of spermatozoa both in the ejaculate and in the AI-dose were significant factors for FH but not for SB suggesting that sperm production is lower and therefore more critical for fertility in 
Mares inseminated in one estrus only had significantly lower foaling rates than mares inseminated in two or more cycles. The number of breeding cycles is the decision of the breeder, depending on choices on financial investments in breeding and when breeding is started and when it is finished for each mare, thus affecting the traits of the mare population. If the first cycle PR is less than $50 \%$, as the $\mathrm{FH}$ in our study had, the mare would need more than three cycles to achieve the goal of a seasonal PR of $80 \%$. In Finland, the FH mares start to cycle later in spring than the SB mares [28], and therefore their breeding season tends to be shorter than that of SB mares. Both the number of inseminated cycles and inseminations per cycle came out as significant factors, emphasizing the importance of giving enough opportunities for the mare to conceive. Two or three inseminations during estrus resulted in a higher PR in FH than one insemination only or four inseminations or more, but in SB all repeated inseminations were better than only one. Similarly, Sieme et al. [29 showed that multiple inseminations (from 2 to $\geq 4$ ) resulted in a higher PR compared to one insemination only. In the study of Batellier et al. [30], a second AI was carried out post-ovulation and resulted in higher PR than one insemination. The beneficial effect of repeated inseminations was not related to the added numbers of spermatozoa but presumably to inseminating close to ovulation or to some unknown factor. In the cooled semen study of Squires et al. [31], mares inseminated twice with $1 \times 10^{9}$ progressively motile sperm on two consecutive days ( 24 and $48 \mathrm{~h}$ after semen collection) had a higher pregnancy rate (64\%) than mares inseminated once with $1 \mathrm{x}$ $10^{9}$ progressively motile sperm (PR 30\%) or those inseminated once with $2 \times 10^{9}$ progressively motile spermatozoa (PR 41\%). However, the mares inseminated only once had $48 \mathrm{~h}$ between $\mathrm{AI}$ and ovulation as compared to $22 \mathrm{~h}$ for the mares inseminated on two consecutive days because hCG was given at the time of the first 
AI. When the time between AI and ovulation was standardized, there was no longer any benefit of holding half of the insemination dose for rebreeding on the following day [32]. It is very likely that the advantage of multiple inseminations during the heat is due to a shortened interval from the last insemination to ovulation.

Although high pregnancy rates are achieved with fresh semen up to three days before ovulation [33], inseminations with cooled semen should be done within $24 \mathrm{~h}$ before ovulation or within 12 to $16 \mathrm{~h}$ after ovulation [29,34]. Heiskanen et al. [35] reported high pregnancy rates with cooled semen stored for 70 or $80 \mathrm{~h}(77 \%$ and $57 \%$, respectively) when the mares were inseminated within $12 \mathrm{~h}$ after ovulation with $2 \mathrm{x}$ $10^{9}$ spermatozoa. Mare management and AI close to ovulation play a major role in equine fertility when inseminating with cooled semen.

\section{Semen and insemination dose}

The type of AV did not affect PR. Unexpectedly, semen collected by open-ended AV did not have significantly higher sperm concentration than semen collected by a Missouri-type AV. Open collection may have been chosen for stallions producing semen with low sperm concentration, as recommended.

The ideal dilution ratio of semen for shipments is 1:4 (semen:extender) to decrease the proportion of SP to less than $20 \%$ [8]. Also, the optimal sperm concentration must be considered, and therefore less extender is added if the sperm concentration of the ejaculate is low [16]. In this material, the mean sperm concentration of the AI dose was between 51 and $54 \times 10^{6} / \mathrm{mL}$, so in many cases more extender could have been added and still be within the minimal concentration of $25 \times 10^{6} / \mathrm{mL}$. One 
explanation for the low dilution rate is the practice to dilute to $40 \mathrm{~mL}$ which is the

316 maximum volume that can be accommodated in the transport box. If motility and concentration are low, the total volume with the extender will readily become too high. Because adequate dilution of semen was seldom done, $82 \%$ of the AI doses contained more than the recommended $20 \%$ SP.

Several studies have shown that SP decreases sperm survival during storage $[7,9,11$, 36-38]. In the present study, the proportion of SP included in the insemination dose did not seem to affect the outcome of the AI, probably because semen was stored for a short period of time. The choice of AV did not affect the results either, showing that sperm survival during a short-term cooled storage is not different when the whole ejaculate is used instead of the sperm-rich part of the ejaculate. Previously, Varner et al. [5] have demonstrated higher motility for the sperm-rich part compared to the whole ejaculate at 12 and $24 \mathrm{~h}$ of storage. According to Kareskoski et al. [36], sperm-rich fractions with low levels of SP maintained a higher level of DNA integrity during 24-h storage than sperm-poor fractions. Although sperm-rich fractions have higher motility and lower DNA fragmentation index, it was not reflected in fertility in our study. satisfactory for cooled semen with a per cycle PR of $47 \%$ and a foaling rate of $70 \%$. However, the median time from collection to AI was only $10 \mathrm{~h}$ which is shorter than in many other countries where it is commonly around $24 \mathrm{~h} \mathrm{[4].}$ 
The total number of spermatozoa in the studied insemination doses was unexpectedly high (from 1.7 to $1.9 \times 10^{9}$ ), which shows that most stallions did not have a large book of mares. The high numbers of spermatozoa could have partly compensated for possible negative effects of high SP content and decrease in progressive motility. On the other hand, damaged and abnormal spermatozoa generate large amounts of reactive oxygen species, and therefore low total sperm count with high PMOT may result in better fertility than high sperm numbers with low PMOT [4]. The material also contained some stallions with semen that had decreased tolerance of storage, as shown by the low progressive motility at the time of AI and by a low PR. These stallions could have benefited from a higher dilution rate.

Progressive sperm motility both before and after shipment and the number of progressively motile sperm in the AI dose at the time of insemination significantly affected the PR. In the Austrian study including 102 doses of transported semen, total motility, PMOT and percentage of morphological sperm defects (all these evaluated at the time of AI) significantly influenced the outcome of AI [4]. In our study, PMOT at the time of semen processing was most often reported as 70 or $80 \%$, with only minimal variation. Cooled shipped semen is not a preferred method to use with subfertile stallions, and this may partly account for the lack of variation in PMOT values. Stud farm staff may also overestimate motility in an attempt to increase the number of doses per ejaculate. It is not easy to evaluate PMOT of stallion sperm, particularly with the microscopes at the stud farms which in our experience do not provide the best visualization. Inadequate dilution of concentrated semen before microscopy results in visualization of higher motility because individual spermatozoa cannot be seen. Microscopic evaluation of progressive motility is subjective and 
varies considerably among readers [39]. Some studies have shown correlations with fertility whereas some others have failed to do so [8, 39]. Despite these limitations, PMOT is still used routinely as a measure of semen quality in field conditions, and the number of progressively motile sperm at the time of AI shows the ability of semen withstand cooling and storage. In addition, it also reflects the quality of semen processing which affects the results with cooled-shipped semen [4]. The common use of this parameter in practice warrants its inclusion in the analyses in this study.

\section{Conclusions}

In conclusion, breed and breed-related mare population characteristics, adequate breeding opportunity, and more than one insemination/estrus in addition to adequate sperm numbers with good progressive motility significantly affect the fertility of inseminations with cooled semen stored for $10 \mathrm{~h}$. Any possible harmful effects of a suboptimal dilution rate and subsequent high proportion of seminal plasma may have been partly compensated by the use of high numbers of spermatozoa in the insemination doses. In stallions whose sperm have poor tolerance of cooling and storage as well as in longer lasting transports, optimal proportion of SP is probably more vital.

Declaration of interests: None.

Funding. This work was supported by Makera funding from the Ministry of Agriculture in Finland. 
Acknowledgements. Suomen Hippos and Terttu Peltonen are thanked for providing us the breeding data and semen transport forms. Special thanks to Tero Wahlberg for performing the statistical analysis of the data.

392

Authorship. MK contributed to analysis and interpretation of the data, drafted the article and approved the final manuscript. HV contributed to acquisition, analysis and interpretation of data, revised the article and approved the final manuscript. A-M V participated in the conception and design of the study and in the analysis and interpretation of data; she also revised the article and approved the final version. TK was responsible for the conception and design of the study, contributed to writing and correction of the manuscript and approved the final version.

400

401

\section{References}

403

404

[1] Katila T, Reilas T, Nivola K, Peltonen T, Virtala A-M. A 15-year survey of reproductive efficiency of Standardbred and Finnhorse trotters in Finland descriptive results. Acta Vet Scand 2010;52:40.

407

[2] Pickett BW, Amann RP. Extension and storage of stallion spermatozoa: a review. Equine Vet Sci 1987;7:289-302. 1997;48:1085-92. 

fractionation and dilution ratio on equine spermatozoal motility parameters. Theriogenology 1987;28:709-23.

[6] Webb GW, Arns MJ, Pool KC. Sperm concentration influences recovery of progressively motile spermatozoa and number of inseminations shipped in conventional containers. J Equine Vet Sci 1993;13:487-9. spermatozoa following in vitro culture $\left(37^{\circ} \mathrm{C}\right)$ and cold-storage $\left(5^{\circ} \mathrm{C}\right)$. Theriogenology 1993;39:291-6. seminal plasma and egg yolk on motion characteristics of cooled stallion spermatozoa. Theriogenology 1992;37:1241-52. processing on cold-stored stallion spermatozoa. Anim Reprod Sci 2001;68:335-6. 

Relationship of seminal plasma level and extender type to sperm motility and DNA integrity. Theriogenology 2005;63:1584-91. removal of seminal plasma on equine spermatozoal motility after cooling and storage. Theriogenology 2000;54:129-36.

[12] Tischner M, Kosiniak K, Bielanski W. Analysis of the pattern of ejaculation in stallions. J Reprod Fert 1974;41:329-35.

[13] Tischner M, Kosiniak K. Bacterial contamination of stallion semen collected by “open” artificial vaginas. Vlaams Diergeneeskundig Tijdschrift 1986;55:90-4. obtained by a new semen collection phantom (Equidame) versus a Missouri artificial vagina. Theriogenology 1999;51:1157-73. Influence of mare age, pre-breeding mare status, breeding method, and stallion on the first cycle pregnancy rates on a large commercial breeding farm. Anim Reprod Sci 2010;121S:S159. [16] Loomis P. Factors affecting the success of artificial insemination with cooled, transported semen. Proc $38^{\text {th }}$ Ann Conv Am Ass Equine Practitioners 1993;629-47. 

and Australian Biosecurity Cooperative Research Centre for Emerging Infectious Disease, 2017. Available at: http://epitools.ausvet.com.au. horse births in France. Reprod Nutr Dev 2004;44:583-95.

[22] Carnevale EM, Ginther OJ. Relationship of age to uterine function and reproductive efficiency in the mare. Theriogenology 1992;37:231-46. 45. 
[24] Bosh KA, Powell D, Shelton B, Zent W. Reproductive performance measures among Thoroughbred mares in central Kentucky during the 2004 mating season. Equine Vet J 2009;41:883-8.

Thoroughbred mares in the Waikato region of New Zealand: 2. Multivariable analyses and sources of variation at the mare, stallion and stud farm level. N Z Vet J 2012;60:335-43.

493

[26] Haadem C, Nødtvedt A, Farstad W, Thomassen R. A retrospective cohort study on fertility in the Norwegian Coldblooded trotter after artificial insemination with cooled, shipped versus fresh extended semen. Acta Vet Scand 2015;57:77.

497 factors affecting reproductive success of Thoroughbred mares and stallions on a commercial stud farm. Reprod Domest Anim 2016;51:181-7.

[28] Koskinen E, Katila T. Onset of luteal activity in non-foaling mares during the early breeding season in Finland. Acta Vet Scand 1991;32:313-8. insemination regimes on fertility in mares. Theriogenology 2003;60:1153-64. under aerobic conditions. Theriogenology 1998;50:229-36. 
512 [31] Squires EL, Brubaker JK, McCue PM, Pickett BW. Effect of sperm number and 513 frequency of insemination on fertility of mares inseminated with cooled semen.

$514 \quad$ Theriogenology 1998;49:743-9. comparison between breeding at 24 hours or at 24 and 48 hours after collection with cooled equine semen. Theriogenology 1998;50:693-8. ovulation on pregnancy rate and embryonic-loss rate in mares. Eq Vet J 1990;22:410-5. transported semen and natural mating relative to ovulation on pregnancy and embryo loss rates in the mare. Reprod Domest Anim 2011;46:678-81. fertility and sperm longevity in fractionated ejaculates. Reprod Domest Anim 2011;46:1073-81. 

or removal on spermatozoal motion characteristics of cooled stallion semen. Theriogenology 1991;35:1059-67.

538 [38] Braun J, Sakai M, Hochi S, Oguri N. Preservation of ejaculated and epididymal stallion spermatozoa by cooling and freezing. Theriogenology 1994;41:809-18.

541

542

[39] Love CC. Relationship between sperm motility, morphology and the fertility of 543 stallions. Theriogenology 2011;76:547-57.

544 
545 Table 1. Pregnancy rate per cycle of mares (mean, 95\% confidence interval ( $\mathrm{Cl}$ ) in different categories). $546 \mathrm{~N}=$ number of inseminated cycles.

\begin{tabular}{|llll|}
\hline Variable & Category & N & $\begin{array}{l}\text { Pregnancy rate } \\
\text { per cycle (95\% Cl) }\end{array}$ \\
\hline Breed & Finnhorse & 889 & $42.2(39.0-45.5)$ \\
& Standardbred & 745 & $52.9(49.3-56.4)$ \\
\hline Artificial vagina & Open-ended & 563 & $47.8(43.7-51.9)$ \\
& Closed & 1003 & $47.4(44.3-50.5)$ \\
& Unknown & 68 & $36.8(26.3-48.6)$ \\
\hline Insemination place & Stud farm/clinic & 771 & $46.7(43.2-50.2)$ \\
& Home stable & 640 & $46.4(42.6-50.3)$ \\
\hline Insemination performed by & Veterinarian & 935 & $47.0(43.8-50.2)$ \\
& Technician & 364 & $46.7(41.6-51.8)$ \\
\hline Number of inseminated estrus cycles & 1 & 1069 & $46.2(43.2-49.2)$ \\
& $\geq 2$ & 565 & $48.7(44.6-52.8)$ \\
\hline Number of inseminations/ estrus & 1 & 1133 & $46.0(43.1-48.9)$ \\
& $\geq 2$ & 501 & $49.5(45.1-53.9)$ \\
\hline Seminal plasma in the insemination & $\leq 25 \%$ & 662 & $48.8(45.0-52.6)$ \\
dose (\% of total volume) & $25.1 \%-33.9 \%$ & 382 & $42.9(38.1-47.9)$ \\
& $\geq 34 \%$ & 578 & $47.6(43.5-51.7)$ \\
\hline M onth & March-M ay & 403 & $47.6(42.8-52.5)$ \\
& June & 640 & $46.7(42.9-50.6)$ \\
& July & 445 & $49.2(44.6-53.8)$ \\
& August-September & 146 & $40.4(32.8-48.5)$ \\
\hline Age of stallion (years) & $2-9$ & 561 & $50.5(46.3-54.6)$ \\
& $10-13$ & 505 & $46.3(42.0-50.7)$ \\
\hline Age of mare (years) & $14-16$ & 325 & $46.8(41.4-52.2)$ \\
& $17-22$ & 203 & $39.9(33.4-46.8)$ \\
\hline & $3-6$ & 516 & $45.2(40.9-49.5)$ \\
& $7-9$ & 320 & $51.9(46.4-57.3)$ \\
& $10-13$ & 459 & $44.4(40.0-49.0)$ \\
& $14-26$ & 339 & $49.0(43.7-54.3)$ \\
\hline
\end{tabular}


Table 2a. Descriptive statistics (mean, standard deviation (SD), median, minimum, and maximum) of cycles resulting in pregnancy or nonpregnancy for Finnhorses. Number of horses per variable is not necessarily the same as the total number of horses in the group because of missing data.

\begin{tabular}{|c|c|c|c|c|c|c|c|c|c|c|}
\hline \multirow[b]{2}{*}{ Variable } & \multicolumn{5}{|c|}{ Cycles resulting in pregnancy $(n=375)$} & \multicolumn{5}{|c|}{ Cycles not resulting in pregnancy $(n=514)$} \\
\hline & Mean & SD & Median & $M$ in & Max & Mean & SD & Median & Min & $\operatorname{Max}$ \\
\hline Age of stallion (years) & 11.8 & 5.3 & 11.0 & 5.0 & 26.0 & 10.7 & 4.9 & 10.5 & 5.0 & 26.0 \\
\hline Age of mare (years) & 11.8 & 4.1 & 12.0 & 3.0 & 21.0 & 12.3 & 4.2 & 13.0 & 3.0 & 22.0 \\
\hline Semen transport time (hours) & 9.4 & 3.2 & 9.7 & 0.8 & 37.0 & 9.8 & 3.6 & 10.1 & 0.5 & 39.0 \\
\hline \multicolumn{11}{|l|}{ Semen quality: ejaculate } \\
\hline Volume (mL) & 64.8 & 33.2 & 60.0 & 10.0 & 180.0 & 59.3 & 29.9 & 55.0 & 5.0 & 150.0 \\
\hline Sperm concentration $\left(10^{6} / \mathrm{mL}\right)$ & 163.7 & 88.2 & 134.0 & 50.0 & 466.0 & 159.8 & 86.1 & 131.5 & 25.0 & 466.0 \\
\hline Total number of spermatozoa $\left(10^{9}\right)$ & 9.1 & 4.3 & 7.9 & 1.3 & 19.9 & 8.1 & 3.7 & 7.5 & 1.3 & 19.7 \\
\hline Progressive sperm motility (\%) * & 75.3 & 8.9 & 80.0 & 20.0 & 80.0 & 73.2 & 11.4 & 80.0 & 20.0 & 80.0 \\
\hline Number of progressively motile spermatozoa $\left(10^{9}\right)$ & 6.8 & 3.3 & 6.2 & 0.5 & 15.9 & 5.9 & 2.9 & 5.7 & 0.7 & 15.8 \\
\hline \multicolumn{11}{|l|}{ Semen quality: insemination dose } \\
\hline Volume $(\mathrm{mL})$ & 35.4 & 11.9 & 40.0 & 16.0 & 77.0 & 35.5 & 12.3 & 40.0 & 15.0 & 100.0 \\
\hline Seminal plasma (proportion of volume) & 0.4 & 0.1 & 0.4 & 0.1 & 0.7 & 0.4 & 0.1 & 0.3 & 0.1 & 0.6 \\
\hline Sperm concentration $\left(10^{6} / \mathrm{mL}\right)$ & 53.7 & 17.7 & 52.8 & 17.0 & 105.3 & 51.1 & 17.5 & 52.0 & 12.5 & 133.3 \\
\hline Total number of spermatozoa $\left(10^{9}\right)$ & 1.8 & 0.7 & 1.7 & 0.7 & 5.0 & 1.7 & 0.7 & 1.5 & 0.6 & 6.0 \\
\hline Number of progressively motile spermatozoa $\left(10^{9}\right)$ & 1.3 & 0.5 & 1.2 & 0.5 & 3.4 & 1.2 & 0.4 & 1.1 & 0.5 & 4.8 \\
\hline Progressive sperm motility (\%) at insemination & 44.3 & 16.8 & 40.0 & 2.0 & 80.0 & 42.9 & 17.8 & 40.0 & 3.0 & 80.0 \\
\hline $\begin{array}{l}\text { Number of progressively motile spermatozoa }\left(10^{9}\right) \text { at } \\
\text { insemination }\end{array}$ & 0.8 & 0.4 & 0.7 & 0.0 & 2.8 & 0.8 & 0.4 & 0.7 & 0.0 & 2.4 \\
\hline Number of inseminations/season & 2.0 & 1.2 & 2.0 & 1.0 & 7.0 & 2.0 & 1.3 & 2.0 & 1.0 & 8.0 \\
\hline Number of inseminated estrus cycles & 1.5 & 0.7 & 1.0 & 1.0 & 4.0 & 1.5 & 0.8 & 1.0 & 1.0 & 5.0 \\
\hline Number of inseminations/ estrus & 1.4 & 0.5 & 1.0 & 1.0 & 3.0 & 1.4 & 0.7 & 1.0 & 1.0 & 5.0 \\
\hline Number of insemination doses sent/stud farm/season & 121.9 & 64.0 & 114.0 & 10.0 & 210.0 & 120.9 & 63.3 & 123.0 & 10.0 & 210.0 \\
\hline
\end{tabular}


Table 2b. Descriptive statistics (mean, standard deviation (SD), median, minimum, and maximum) of cycles resulting in pregnancy or nonpregnancy for Standardbreds. Number of horses per variable is not necessarily the total number of horses in the group.

\begin{tabular}{|c|c|c|c|c|c|c|c|c|c|c|}
\hline \multirow{2}{*}{\begin{tabular}{|l|} 
Variable \\
\end{tabular}} & \multicolumn{5}{|c|}{ Cycles resulting in pregnancy $(n=394)$} & \multicolumn{5}{|c|}{ Cycles not resulting in pregnancy $(n=351)$} \\
\hline & Mean & SD & Median & Min & Max & Mean & SD & Median & Min & Max \\
\hline Age of stallion (years) & 9.0 & 4.7 & 7.0 & 3.0 & 24.0 & 9.0 & 4.5 & 7.0 & 3.0 & 24.0 \\
\hline Age of mare (years) & 10.7 & 3.9 & 10.0 & 2.0 & 21.0 & 11.0 & 3.8 & 10.0 & 2.0 & 21.0 \\
\hline Semen transport time (hours) & 10.4 & 3.0 & 10.4 & 2.3 & 27.0 & 9.9 & 3.4 & 10.0 & 1.5 & 29.8 \\
\hline \multicolumn{11}{|l|}{ Semen quality: ejaculate } \\
\hline Volume $(\mathrm{mL})$ & 53.9 & 23.9 & 53.0 & 10.0 & 175.0 & 49.9 & 24.9 & 50.0 & 10.0 & 136.0 \\
\hline Sperm concentration $\left(10^{6} / \mathrm{mL}\right)$ & 217.7 & 106.7 & 186.0 & 11.0 & 612.0 & 231.6 & 118.1 & 195.0 & 29.0 & 613.0 \\
\hline Total number of spermatozoa $\left(10^{9}\right)$ & 8.9 & 3.2 & 8.8 & 0.9 & 19.7 & 9.1 & 3.7 & 8.9 & 1.7 & 19.0 \\
\hline Progressive sperm motility (\%)* & 72.8 & 8.4 & 70.0 & 40.0 & 80.0 & 71.4 & 10.0 & 70.0 & 40.0 & 80.0 \\
\hline Number of progressively motile spermatozoa $\left(10^{9}\right)$ & 6.4 & 2.6 & 6.4 & 0.8 & 15.7 & 6.5 & 2.9 & 6.3 & 0.8 & 14.8 \\
\hline \multicolumn{11}{|l|}{ Semen quality: insemination dose } \\
\hline Volume $(\mathrm{mL})$ & 36.6 & 10.0 & 40.0 & 18.0 & 120.0 & 36.0 & 10.9 & 40.0 & 20.0 & 120.0 \\
\hline Seminal plasma (proportion of volume) & 0.3 & 0.1 & 0.3 & 0.1 & 0.6 & 0.3 & 0.1 & 0.3 & 0.1 & 0.7 \\
\hline Sperm concentration $\left(10^{6} / \mathrm{mL}\right)$ & 52.5 & 16.1 & 50.5 & 3.1 & 104.8 & 54.5 & 15.7 & 51.5 & 19.0 & 1115.3 \\
\hline Total number of spermatozoa $\left(10^{9}\right)$ & 1.8 & 0.5 & 1.8 & 0.1 & 4.2 & 1.9 & 0.5 & 1.8 & 0.8 & 4.1 \\
\hline Number of progressively motile spermatozoa $\left(10^{9}\right)$ & 1.3 & 0.4 & 1.3 & 0.1 & 5.4 & 1.3 & 0.3 & 1.3 & 0.6 & 2.8 \\
\hline Progressive sperm motility (\%) at insemination & 50.7 & 14.5 & 50.0 & 10.0 & 80.0 & 45.6 & 17.1 & 45.0 & 2.0 & 80.0 \\
\hline $\begin{array}{l}\text { Number of progressively motile spermatozoa }\left(10^{9}\right) \text { at } \\
\text { insemination }\end{array}$ & 0.9 & 0.3 & 0.9 & 0.2 & 2.0 & 0.8 & 0.4 & 0.8 & 0.0 & 2.2 \\
\hline Number of inseminations/ season & 1.9 & 1.2 & 2.0 & 1.0 & 7.0 & 1.9 & 1.3 & 1.0 & 1.0 & 9.0 \\
\hline Number of inseminated estrus cycles & 1.4 & 0.7 & 1.0 & 1.0 & 4.0 & 1.4 & 0.7 & 1.0 & 1.0 & 4.0 \\
\hline Number of inseminations/ estrus & 1.4 & 0.6 & 1.0 & 1.0 & 5.0 & 1.3 & 0.6 & 1.0 & 1.0 & 5.0 \\
\hline Number of insemination doses sent/stud farm/season & 139.3 & 62.0 & 132.0 & 10.0 & 210.0 & 134.9 & 61.9 & 132.0 & 10.0 & 210.0 \\
\hline
\end{tabular}


Table 3. Crude logistic regressions for pregnancy per cycle: odds ratio (OR), 95\% confidence interval (Cl)

554 and Wald's p-value (with stud farm, stallion and mare as random effects). $\mathrm{N}=$ number of cycles.

\begin{tabular}{|c|c|c|c|c|}
\hline Variable & $\mathbf{N}$ & OR & $95 \% \mathrm{Cl}$ & $\mathbf{p}$ \\
\hline Breed: Standardbred vs. Finnhorse & 1634 & 1.51 & $1.11-2.08$ & 0.010 \\
\hline Insemination place: stud farm/clinic vs. home stable & 1411 & 1.01 & $0.81-1.26$ & 0.917 \\
\hline Insemination performed by veterinarian vs. technician & 1299 & 1.01 & $0.78-1.30$ & 0.954 \\
\hline Number of inseminated estrus cycles: $\geq 2$ vs. 1 & 1634 & 1.57 & $1.28-1.93$ & $<0.0001$ \\
\hline Number of inseminations/estrus: $\geq 2$ vs. 1 & 1634 & 1.22 & $0.99-1.51$ & 0.069 \\
\hline $\begin{array}{l}\text { Seminal plasma in the insemination dose (\% of total } \\
\text { volume): }\end{array}$ & 1057 & & & 0.177 \\
\hline$\leq 25 \%$ vs. $\geq 34 \%$ & & 1.05 & $0.84-1.31$ & 0.670 \\
\hline $25.1-33.9 \%$ vs. $\geq 34 \%$ & & 0.83 & $0.64-1.08$ & 0.157 \\
\hline Weekday: Saturday-Thursday vs. Friday & 1634 & 1.03 & $0.84-1.26$ & 0.793 \\
\hline Month: & 1634 & & & 0.386 \\
\hline June vs. March-M ay & & 1.05 & $0.82-1.36$ & 0.689 \\
\hline July vs. M arch-M ay & & 1.19 & $0.90-1.57$ & 0.226 \\
\hline August-September vs. March-M ay & & 0.87 & $0.59-1.30$ & 0.494 \\
\hline Number of insemination doses sent/stud farm/season & 1634 & & & 0.750 \\
\hline $100-149$ vs. $<100$ & & 1.17 & $0.68-2.00$ & 0.574 \\
\hline$\geq 150$ vs. $<100$ & & 1.20 & $0.69-2.10$ & 0.524 \\
\hline Age of mare: & 1594 & & & 0.106 \\
\hline $2-9$ vs. $17-22$ years & & 1.48 & $1.06-2.06$ & 0.022 \\
\hline $10-13$ vs. $17-22$ years & & 1.21 & $0.86-1.69$ & 0.280 \\
\hline $14-16$ vs. $17-22$ years & & 1.34 & $0.93-1.92$ & 0.117 \\
\hline Age of stallion: & 1634 & & & 0.742 \\
\hline $3-6$ vs. $14-26$ years & & 0.96 & $0.63-1.46$ & 0.838 \\
\hline $7-9$ vs. $14-26$ years & & 1.19 & $0.76-1.84$ & 0.447 \\
\hline $10-13$ vs. $14-26$ years & & 1.01 & $0.68-1.50$ & 0.963 \\
\hline Semen transport time (hours) & 1474 & 1.00 & $0.97-1.04$ & 0.836 \\
\hline \multicolumn{5}{|l|}{ Semen quality: ejaculate } \\
\hline Volume $(\mathrm{mL})$ & 1097 & 1.00 & $1.00-1.01$ & 0.140 \\
\hline Sperm concentration $\left(10^{6} / \mathrm{mL}\right)$ & 1634 & 1.00 & $1.00-1.00$ & 0.893 \\
\hline Total number of spermatozoa $\left(10^{9}\right)$ & 1097 & 1.00 & $1.00-1.01$ & 0.164 \\
\hline Progressive sperm motility (\%)* & 1611 & 5.33 & $1.30-21.8$ & 0.020 \\
\hline Number of progressively motile spermatozoa $\left(10^{9}\right)$ & 1083 & 1.04 & $0.99-1.10$ & 0.097 \\
\hline \multicolumn{5}{|l|}{ Semen quality: insemination dose } \\
\hline Volume (mL) & 1629 & 1.01 & $1.00-1.02$ & 0.175 \\
\hline Seminal plasma (proportion of volume) & 1622 & 0.93 & $0.31-2.83$ & 0.901 \\
\hline Sperm concentration $\left(10^{6} / \mathrm{mL}\right)$ & 1622 & 1.00 & $0.99-1.01$ & 0.784 \\
\hline Total number of spermatozoa $\left(10^{9}\right)$ & 1623 & 1.17 & $0.97-1.42$ & 0.108 \\
\hline Progressive sperm motility (\%) at insemination & 787 & 3.53 & $1.46-8.51$ & 0.005 \\
\hline $\begin{array}{l}\text { Number of progressively motile sperm }\left(10^{9}\right) \text { at } \\
\text { insemination }\end{array}$ & 781 & 1.63 & $1.10-2.41$ & 0.015 \\
\hline
\end{tabular}


Table 4. M ultivariable logistic regression models for pregnancy per cycle: odds ratio (OR), 95\% confidence interval $(\mathrm{Cl})$, and Wald's $p$-value (with mare, stallion, and stud farm as random effects), $\mathrm{n}=$ number of cycles.

\begin{tabular}{|c|c|c|c|}
\hline \multicolumn{4}{|l|}{ Multivariable logistic regression models I - III } \\
\hline \multicolumn{4}{|l|}{ Model I ( $n=1571)$} \\
\hline Variables & OR & $95 \% \mathrm{Cl}$ & $\mathbf{p}$ \\
\hline Breed (Standardbred vs. Finnhorse) & 1.56 & $1.13-2.16$ & 0.007 \\
\hline Number of inseminated estrus cycles ( $\geq 2$ vs. 1 cycle) & 1.54 & $1.25-1.90$ & $<0.0001$ \\
\hline Age of mare: & & & 0.163 \\
\hline 2-9 vs. $17-22$ years & 1.41 & $0.99-2.01$ & 0.057 \\
\hline $10-13$ vs. $17-22$ years & 1.15 & $0.80-1.65$ & 0.440 \\
\hline $14-16$ vs. $17-22$ years & 1.38 & $0.94-2.02$ & 0.104 \\
\hline $\begin{array}{l}\text { Progressive sperm motility in the } \\
\text { ejaculate/insemination dose (\%) }\end{array}$ & 6.20 & $1.56-24.66$ & 0.010 \\
\hline \multicolumn{4}{|l|}{ M odel II $(n=758)$} \\
\hline Variables & OR & $95 \% \mathrm{Cl}$ & $\mathbf{p}$ \\
\hline Breed (Standardbred vs. Finnhorse) & 1.43 & $0.97-1.22$ & 0.073 \\
\hline Number of inseminated estrus cycles ( $\geq 2$ vs. 1 cycle) & 1.56 & $1.15-2.12$ & 0.004 \\
\hline Age of mare: & & & 0.260 \\
\hline 2-9 vs. $17-22$ years & 1.57 & $0.92-2.68$ & 0.097 \\
\hline $10-13$ vs. $17-22$ years & 1.29 & $0.75-2.21$ & 0.355 \\
\hline $14-16$ vs. $17-22$ years & 1.66 & $0.93-2.98$ & 0.089 \\
\hline $\begin{array}{l}\text { Progressive sperm motility in the } \\
\text { ejaculate/ insemination dose (\%) }\end{array}$ & 14.52 & $2.58-81.75$ & 0.003 \\
\hline $\begin{array}{l}\text { Number of progressively motile spermatozoa in the } \\
\text { insemination dose }\left(10^{9}\right) \text { at insemination }\end{array}$ & 1.6 & $1.05-2.42$ & 0.028 \\
\hline
\end{tabular}


Table 5. M ultivariable logistic regression models for pregnancy rates per cycle in Finnhorses and Standardbred stallions: odds ratio (OR), 95\% confidence interval $(\mathrm{Cl})$, and Wald's p-value (with mare, stallion, and stud farm as random effects), $n=$ number of cycles.

\begin{tabular}{|c|c|c|c|}
\hline \multicolumn{4}{|c|}{ Model for Finnhorses ( $n=602$ ); stud farm and mare as random effects } \\
\hline Variables & OR & $95 \% \mathrm{Cl}$ & $\mathbf{p}$ \\
\hline Number of inseminations/cycle: & & & 0.141 \\
\hline 2 vs. 1 & 1.18 & $0.78-1.79$ & 0.431 \\
\hline 3 vs. 1 & 1.66 & $1.04-2.66$ & 0.035 \\
\hline$\geq 4$ vs. 1 & 0.89 & $0.51-1.57$ & 0.690 \\
\hline Total number of spermatozoa in the ejaculate $\left(10^{9}\right)$ & 1.01 & $1.00-1.01$ & 0.013 \\
\hline $\begin{array}{l}\text { Progressive sperm motility in the ejaculate/ } \\
\text { insemination dose (\%) }\end{array}$ & 38.00 & $3.38-427.21$ & 0.003 \\
\hline $\begin{array}{l}\text { Total number of spermatozoa }\left(10^{9}\right) \text { in the insemination } \\
\text { dose }\end{array}$ & 1.73 & $1.21-2.48$ & 0.003 \\
\hline \multicolumn{4}{|c|}{ M odel for Standardbreds $(n=350) ;$ mare as the random effect } \\
\hline $\begin{array}{l}\text { Variables } \\
\text { Number of inseminations/cycle }\end{array}$ & OR & $95 \% \mathrm{Cl}$ & $\begin{array}{c}p \\
0.017\end{array}$ \\
\hline 2 vs. 1 & 2.14 & $1.27-3.62$ & 0.005 \\
\hline 3 vs. 1 & 1.95 & $1.02-3.72$ & 0.044 \\
\hline$\geq 4$ vs. 1 & 2.03 & $0.97-4.26$ & 0.062 \\
\hline Progressive sperm motility (\%) at insemination & 10.14 & $2.31-44.47$ & 0.002 \\
\hline
\end{tabular}

